\title{
An unusual cause of acute abdomen: Post-colonoscopy appendicitis
}

\author{
Mehmet Tolga Kafadar' ${ }^{1 D}$, İsmail Bilgiç², Seyfi Kartal ${ }^{3}$, Sefa Güliter ${ }^{4}$
}

ABSTRACT

ORCID ID of the author: M.T.K. 0000-0002-9178-7843.

Cite this paper as:

Kafadar MT, Bilgiç i, Kartal S,

Güliter $S$. An unusual cause

of acute abdomen:

Post-colonoscopy

appendicitis. Turk J Surg

2018; 34(4):340-341.

${ }^{1}$ Clinic of General Surgery, Health Sciences University Mehmet

Akif İnan Training and Research Hospital, Şanlıurfa, Turkey

${ }^{2}$ Clinic of General Surgery, Ankara Umut Hospital, Ankara, Turkey

${ }^{3}$ Clinic of Anaesthesiology and Reanimation, Health Sciences University Kanuni Training and Research Hospital, Trabzon, Turkey

${ }^{4}$ Clinic of Gastroenterology, Minasera Aldan Hospital, Ankara, Turkey

This study was presented at the $13^{\text {th }}$ National

Hepatogastroenterology Congress, 27 April-1 May 2016,

Antalya, Turkey.

\section{Corresponding Author}

Mehmet Tolga Kafadar e-mail:drtolgakafadar@hotmail. com

Received: 18.11.2015 Accepted: 19.02.2016

CCopyright 2018

by Turkish Surgical Association
Colonoscopy is commonly performed for diagnostic and therapeutic purposes and has a relatively low morbidity rate. Nevertheless, it is necessary for operators to be aware of the rare complications of colonoscopy due to a large number of procedures performed in daily practice. Acute appendicitis is an unusually rare occurrence after colonoscopy, with no clear association being found between the colonoscopy and acute appendicitis. A rapid diagnosis of this complication is possible by widespread awareness in surgeons regarding this condition. Acute appendicitis cannot be reliably resulted in as the cause of acute abdominal pain due to relatively subtle signs, symptoms, and studies performed for bowel perforation. The diagnosis of postcolonoscopy appendicitis is difficult, and strategies for its treatment show significant variation. This report presents a patient having undergone urgent laparotomy within $12 \mathrm{~h}$ after colonoscopy on having signs and symptoms of acute appendicitis-induced peritonitis.

Keywords: Appendicitis, colonoscopy, fecalith

\section{INTRODUCTION}

The aim of performing colonoscopy is to detect and treat any lesion or pathology in the colon or distal small intestine; its use in clinical practice has witnessed a recent dramatic increase. Colonoscopy is well known to cause intestinal perforation and hemorrhage in some patients, albeit at a very low rate (1). Appendicitis, on the other hand, is much rarer after colonoscopy. Fortunately, a timely and effective intervention is possible when this condition is promptly identified (2). Here we present a 34-year-old man who developed acute abdomen after colonoscopy.

\section{CASE PRESENTATION}

A 34-year-old man underwent screening colonoscopy for investigation of iron-deficiency anemia. The patient had an unremarkable bowel preparation and denied any abdominal pain, vomiting, or nausea before the procedure. Colonoscopy was performed according to the standard protocol using a video colonoscope. The endoscope was advanced to the cecum, and the appendix orifice was visualized. No abnormality was found during the colonoscopy, and he underwent colonoscopy without complication. He was observed for $2 \mathrm{~h}$. Over the $2 \mathrm{~h}$, marked abdominal pain developed acutely. Physical examination revealed right lower quadrant tenderness and rebound pain. Blood pressure was $110 / 70 \mathrm{mmHg}$, pulse rate was $92 / \mathrm{min}$, and body temperature was $38^{\circ} \mathrm{C}$. Laboratory data showed a white cell count of 19.600 / $\mathrm{mm}^{3}$ and CRP of $30.8 \mathrm{mg} / \mathrm{L}$. No free intraabdominal air was identified on erect chest X-ray. There were no signs or symptoms of appendicitis before colonoscopy. Abdominal ultrasonography performed after the patient complained of right lower abdominal pain showed an inflamed appendix. A computed tomography (CT) scan was promptly obtained to investigate other causes of his abdominal pain and an appendix containing fecalith, which distended to $15 \mathrm{~mm}$, was identified (Figure 1). The patient was brought to the surgery room due to presence of acute peritonitis and was found to have a swollen and inflamed appendix (Figure 2) requiring open appendectomy with no additional surgical intervention and drain placement. The surgery was initiated by laparoscopy but converted to open surgery because of retrocecal localization of appendix and difficulty experienced during dissection. The cecum and right colon were inspected and found to be uninjured. The patient was discharged with full recovery 2 days later. Histopathological examination confirmed the diagnosis of acute appendicitis. His postoperative course was unremarkable. Informed consent was obtained from the patient who participated in this case.

\section{DISCUSSION}

Colonoscopy offers an effective diagnostic and therapeutic management opportunity for colorectal disorders. Although it is relatively safe, it is not entirely immune to risks. Rare major complications include hemorrhage, colonic perforation, and postpolypectomy syndrome. Minor complications may occur more commonly and include abdominal pain, vomiting, nausea, intestinal spasm, and mucosal tears in the lining of the colon (1). 

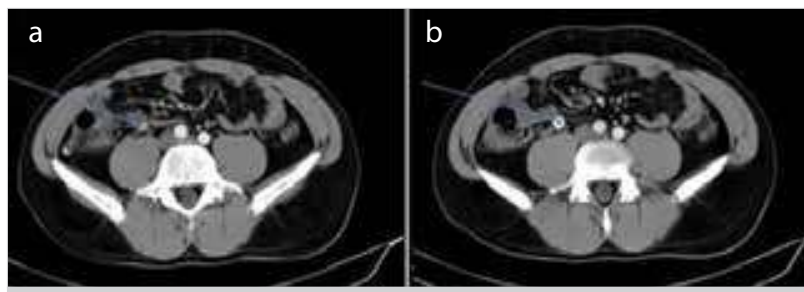

Figure 1. a, b. Axial abdominal CT scan image showing a distended appendix (a) and an intraluminal fecalith (b)

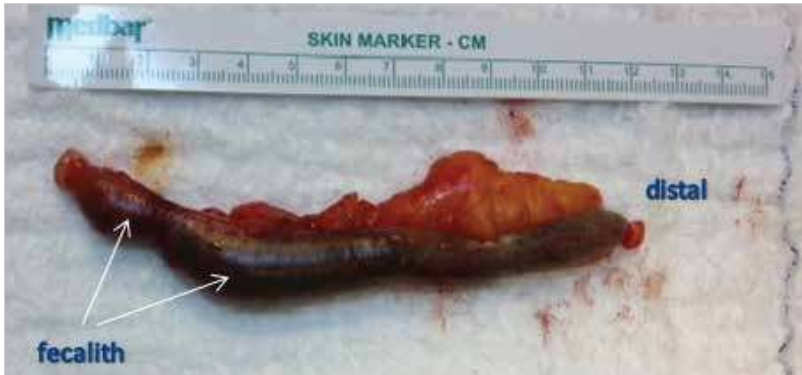

Figure 2. The intraoperative findings revealed acute appendicitis; lumen of the appendix was filled with fecal material

Acute appendicitis postcolonoscopy is an extremely rare occurrence. Appendicitis after colonoscopy was first reported by Houghton and Aston; there are only 12 such cases reported in the medical literature so far (2). Three cases were reported by Vender et al. (3) from two centers with a total volume of 8000 colonoscopies, thus indicating an appendicitis incidence of around $0.038 \%$. This figure is well below that of other complications of colonoscopy, including hemorrhage $(0.21 \%)$, colonic perforation $(0.1 \%)$, or abdominal pain $(0.09 \%)$. However, unfortunately, acute appendicitis is mostly missed because abdominal pain is a common finding after colonoscopy, mostly due to retained gas or colonic spasm after the procedure (1).

Although acute appendicitis after colonoscopy may simply be a coincidence having nothing to do with colonoscopy, Occam's razor may suggest otherwise. Our patient did not have concurrent coincidental appendicitis, as the appendiceal orifice visualized at colonoscopy was normal along with the caecum and terminal ileum, indicating no evidence of inflammatory bowel disease. The pathophysiology of this condition is not completely understood. Based on certain endoscopic features and the timing of occurrence, several theories have been put forward, including barotrauma induced by overinsufflation, direct trauma of appendiceal lumen caused by accidental luminal entry, and pushing feces into the lumen, thereby obstructing the orifice and worsening a previously silent disease or inflammation (4).

Although acute appendicitis is well known for producing abdominal pain, its detection and management are often delayed when it occurs after colonoscopy. This may derive from a symptom set shared with some more common colonoscopy complications such as colonic perforation and postpolypectomy syndrome (5). Therefore, radiological imaging is important for making the correct diagnosis. Another reason may be the unawareness of such a complication after colonoscopy.

Sometimes, multiple mechanisms may be operational in the development of this complication; this holds especially true when patients have some anatomical or immunological abnormalities creating a tendency for inflammation, which is fur- ther corroborated by the preparatory phase of the procedure or the procedure itself. Our patient had no previous disorder creating any tendency for an appendiceal disease, and the clinical presentation was consistent with a newly occurring appendicitis $2 \mathrm{~h}$ after the colonoscopy procedure; we therefore suggest that our procedure cause the complication by forcing a fecalith into the appendiceal lumen. Our theory was confirmed by a preoperative CT scan that showed appendicoliths as well as the postoperative pathology report stating the same finding. While CT is helpful to diagnosis, lack of inflammatory alterations in the appendiceal lumen in the early stages of the condition often preclude the optimal use of this modality (6).

Most patients affected by postcolonoscopy appendicitis are treated by open appendectomy, and the laparoscopic approach is another alternative. Laparotomy may be preferred to avoid colonoscopic bowel perforation and intraabdominal sepsis. Considering appendicitis as a potential complication may have allowed a laparoscopic approach in the beginning. Delayed identification of this condition may prevent early appendectomy from being performed with an associated increase in the complication rate (7).

\section{CONCLUSION}

Appendicitis is an important, albeit fairly rare, complication of colonoscopy, and it can easily lead to diagnostic confusion with other potential complications. While a rapid diagnosis allows timely intervention and improved outcomes, delays in detection may result in serious adverse events. It is therefore vital for clinicians to keep in mind that appendicitis is a potential cause of abdominal pain after colonoscopy.

Informed Consent: Written informed consent was obtained from patient who participated in this study.

Peer-review: Externally peer-reviewed.

Author Contributions: Concept - M.T.K., I.B.; Design - M.T.K., S.K.; Supervision - M.T.K., I.B., S.G.; Resource - M.T.K., S.K.; Materials - M.T.K., I.B.; Data Collection and/or Processing - M.T.K., S.G.; Analysis and/or Interpretation - M.T.K., I.B.; Literature Search - M.T.K., S.K.; Writing Manuscript - M.T.K.; Critical Reviews - M.T.K., I.B., S.G.

Conflict of Interest: The authors have no conflicts of interest to declare.

Financial Disclosure: The authors declared that this study has received no financial support.

\section{REFERENCES}

1. Viiala C, Zimmerman M, Cullen DJ, Hoffman NE. Complication rates of colonoscopy in an Australian teaching hospital environment. Intern Med J 2003; 33: 355-359. [CrossRef]

2. Houghton A, Aston N. Appendicitis complicating colonoscopy. Gastrointest Endosc 1988; 34: 489. [CrossRef]

3. Vender R, Larson J, Garcia J, Topazian M, Ephraim P. Appendicitis is a rare complication of colonoscopy. Gastrointest Endosc 1995; 41: 514-516. [CrossRef]

4. Shaw D, Gallardo G, Basson MD. Post-colonoscopy appendicitis: A case report and systematic review. World J Gastrointest Surg 2013; 5: 259-263. [CrossRef]

5. Takagi Y, Abe T. Appendicitis following endoscopic polypectomy. Endoscopy 2000; 32: S49.

6. Bildzukewicz NA, Weinstein MS. Appendicitis following virtual colonoscopy: a case report. J Gastrointest Surg 2012; 16: 2291-2293. [CrossRef]

7. Mason RJ, Moazzez A, Sohn H, Katkhouda N. Meta-analysis of randomized trials comparing antibiotic therapy with appendectomy for acute uncomplicated (no abscess or phlegmon) appendicitis. Surg Infect (Larchmt) 2012; 13: 74-84. [CrossRef] 